\title{
Inter-hospital transport of the child with critical cardiac disease
}

\author{
Padmanabhan Ramnarayan, ${ }^{1}$ Zafurallah Intikhab, ${ }^{2,3,4}$ Neil Spenceley, ${ }^{5}$ Ilias Iliopoulos, ${ }^{6}$ Alana Duff, ${ }^{7}$ \\ Johnny Millar ${ }^{8}$ \\ ${ }^{1}$ Children's Acute Transport Service (CATS), Great Ormond Street Hospital NHS Foundation Trust, London; \\ ${ }^{2}$ Birmingham Children's Hospital NHS Foundation Trust, Birmingham; ${ }^{3}$ Chain of Hope, London, United Kingdom; \\ ${ }^{4}$ International Children's Heart Foundation, Memphis, Tennessee, United States of America; ${ }^{5}$ Paediatric Intensive Care \\ Unit, Royal Children's Hospital, Glasgow, United Kingdom; ${ }^{6}$ Cardiac Intensive Care, Heart Institute, Cincinnati \\ Children's Hospital Medical Center, Cincinnati, Obio, United States of America; ${ }^{7}$ Paediatric Retrieval Service \\ (ScotSTAR), Glasgow Airport, United Kingdom; ${ }^{8}$ Paediatric Intensive Care Unit, Royal Children's Hospital and \\ Murdoch Children's Research Institute, Melbourne, Australia
}

\begin{abstract}
Centralisation of services such as cardiology, cardiac surgery, and intensive care in many parts of the world has resulted in the need to safely transport children with critical cardiac disease from local hospitals to specialist centres for diagnostic, surgical, and/or critical care intervention. The transport of this cohort of children, whether locally or internationally, can present specific clinical and logistical challenges. An international group of clinicians with expertise in cardiac care and critical care transport worked together to summarise current clinical practice relating to key areas of transport. This expert review covers the transport of the child with critical cardiac disease in terms of referral triage and advice, enabling optimal management of locally available resources, clinical stabilisation before transport, international air transport, transport considerations in low- and middleincome countries, and the transport of children with specific cardiac conditions. As specialist services are centralised to fewer large centres, the need for safe and timely inter-hospital transport of children with critical cardiac disease is only expected to rise in the future. The key principles outlined in this review will be helpful for practitioners in global settings who are, or might be, involved in transporting children between hospitals.
\end{abstract}

Keywords: Inter-hospital transport; paediatric critical care; critical heart disease; resource-limited settings

Received: 15 September 2017; Accepted: 15 September 2017

\section{Background}

Owing to the centralisation of services such as cardiology, cardiac surgery, and intensive care in many parts of the world, children with critical cardiac disease presenting to local hospitals frequently require stabilisation and safe transport to specialist centres for diagnostic, surgical, and/or critical care intervention. $^{1-3}$ The inter-hospital transport of this group of patients can present particular clinical and logistical challenges. ${ }^{4}$ Children with critical cardiac disease often have greater severity of illness and

Correspondence to: J. Millar, Paediatric Intensive Care Unit, Royal Children's Hospital, Parkville, Vic 3052, Australia. Tel: +61 39345 5211; Fax: +61 3 93459179; E-mail: johnny.millar@rch.org.au require significant stabilisation before transport; their complex circulatory physiology, particularly in children who have had multiple previous cardiac interventions, is more likely to be affected by events common during transport such as accelerationdeceleration and changes in ventilation; the potential for rapid physiological deterioration means that close monitoring by experienced staff is a crucial consideration; and the absence of a clear cardiac diagnosis in many cases complicates clinical decision-making and the selection of an appropriate destination unit. Inter-hospital transport of children with critical cardiac disease should usually be undertaken by a team with specialist training and experience in the areas of cardiac critical care and transport. ${ }^{5}$ 
In this expert review, we will cover aspects related to the transport of critically ill children with cardiac disease such as referral triage and advice, transport decision-making, aeromedical and international transport, and the management of specific cardiac conditions during transport.

\section{Referral triage and advice}

The main purpose of triage before transport is to assess the clinical condition of the patient, including whether a cardiac diagnosis is confirmed and how critically ill the patient is; assess the local capabilities and resources available - for example, availability of staff to perform critical interventions and diagnostic tests, and whether telemedicine is available and appropriate; and provide recommendations to stabilise the patient while waiting for a transport team to arrive. ${ }^{6}$ Advice given should be tailored to the clinical scenario and the capabilities of the referring centre. At the same time, there must be a recognition that some urgent interventions cannot wait until the arrival of the transport team. Empowering local staff to use available resources effectively is an important part of the triage process.

\section{Clinical assessment and advice}

Clinical assessment and advice provision should be completed rapidly and, if necessary, in consultation with relevant specialists (cardiologist, cardiac intensivist). A systematic and structured approach is important. Key points relating to clinical assessment and advice are shown in Table 1.

\section{Assessment and optimisation of local resources}

Children with critical cardiac disease are often severely ill and require the most experienced staff available to care for them. A team-based approach should be adopted. ${ }^{7}$ Staff with airway skills and those with knowledge related to the cardiac condition should be available. While in some settings this might be the cardiac intensive care team, in many settings members of anaesthetic and paediatric teams should be present during stabilisation to complement each other's skills and knowledge. Neonatologists should be involved in acute care of neonates where possible. In settings in which local staff resources are limited, the most experienced person (or people) with advanced life support skills should lead the clinical team.

The unavailability of equipment and trained operators may limit the capability of local staff. Staff with even basic echocardiographic skills are likely to be unavailable in many settings, highlighting the importance of clinical assessment in cardiac disease. Anaesthetic staff may be unfamiliar with intubation in children or lack advanced airway equipment supraglottic airway devices can provide a safe alternative option to manage the airway and may provide effective ventilation in such cases. ${ }^{8}$ Intraosseous access can serve as an effective alternative to central venous access even when staff have limited experience in obtaining venous access.

Ongoing advice from the remote specialist centre (or transport team) is important to support the local hospital during stabilisation. Traditional telephonebased approaches may be replaced by video consultation models in the future. ${ }^{10}$ Advances in technology mean that even mobile phones can be used for this purpose. Although the existing evidence base is weak, adoption of telemedicine has been shown to improve the quality of advice provided during paediatric critical care referral. ${ }^{11}$

\section{Transport}

\section{General principles}

The general principles related to the transport of the child with critical cardiac disease are as follows:

- As interventions while travelling in the ambulance or aircraft can be technically difficult and associated with a higher risk of complications, stabilisation is best performed at the referring hospital before transport.

- Achieving physiological stability may not be possible in some scenarios where a definitive intervention can only be performed at the specialist centre. Typical examples are transposition of the great arteries with poor mixing - where an urgent balloon atrial septostomy is required - and obstructed total anomalous pulmonary venous return - where emergency surgery is required. Prior awareness of these conditions should highlight to the transport team that once life-saving interventions such as intubation and ventilation have been performed, the child should be rapidly transferred to the specialist centre. When there is no clear diagnosis, failure to respond to key interventions as expected - for example, refractory severe hypoxia despite adequate ventilation - should warn the transport team that a "time-critical" transfer is required. In rare circumstances in which "time-critical" transport involves very long distances, it may be necessary to stabilise the child before transport by placing them on extracorporeal life support for the transport. ${ }^{12}$

\section{Transport logistics}

Type of team. The risk of complications during transport and a strong evidence-base supporting the use of specialist retrieval teams to perform critical care transports suggest that most children with 
Table 1. Key points relating to clinical assessment and advice during triage for transport.

\begin{tabular}{|c|c|}
\hline Domains & Clinical assessment \\
\hline irway & $\begin{array}{l}\text { Presence of stridor and its nature - inspiratory: croup, } \\
\text { subglottic stenosis; biphasic: tracheal/bronchial obstruction } \\
\text { due to tumour, double aortic arch, or absent pulmonary valve } \\
\text { syndrome } \\
\text { Presence of stertor - functional airway obstruction due to poor } \\
\text { conscious level } \\
\text { Presence of, or suspected, genetic syndromes with } \\
\text { dysmorphism such as Trisomy 21, Pierre Robin sequence, Di } \\
\text { George syndrome } \\
\text { Previous anaesthetic history of difficult intubation } \\
\text { Last oral/enteral feed }\end{array}$ \\
\hline Breathing & $\begin{array}{l}\text { Signs of respiratory distress (tachypnoea, grunting, recessions) } \\
\text { Extent of hypoxia and hypercarbia } \\
\text { Presence of wheeze and/or crackles on auscultation } \\
\text { Signs of lung disease on chest X-ray (consolidation, collapse, } \\
\text { pneumothorax, effusions) }\end{array}$ \\
\hline Circulation & $\begin{array}{l}\text { Family history of neonatal deaths, thythm disturbances, or } \\
\text { CHD } \\
\text { Maternal history of rubella, drug use, or diabetes } \\
\text { History of feeding and growth } \\
\text { Rapidity of onset of symptoms } \\
\text { Clinical signs of shock (tachycardia, poor volume pulses, poor } \\
\text { perfusion), cyanosis, finger clubbing, femoral pulse volume, } \\
\text { 4-limb blood pressure, heart murmur, pre- and post-ductal } \\
\text { pulse oximetry and any gradient, hepatomegaly } \\
\text { Chest X-ray signs of cardiomegaly, lung vascular markings } \\
\text { (oligaemia versus plethoric lungs), vertebral or rib anomalies, } \\
\text { classic findings such as boot-shaped heart or snowman } \\
\text { appearance }\end{array}$ \\
\hline Neurology & $\begin{array}{l}\text { Level of consciousness - coma may indicate profound } \\
\text { circulatory collapse or prolonged severe hypoxia or, in older } \\
\text { children, a stroke } \\
\text { History of seizures or abnormal movements, which may be seen } \\
\text { following cardiopulmonary bypass surgery or associated with } \\
\text { multisystem genetic diagnoses such as Trisomy } 21 \text { or tuberous } \\
\text { sclerosis } \\
\text { History of syncope }\end{array}$ \\
\hline lic & $\begin{array}{l}\text { Blood sugar level } \\
\text { Serum calcium, persistently low in hypoparathyroidism seen } \\
\text { with Di George syndrome, magnesium, potassium and } \\
\text { sodium, low with chronic diuretic use, } \\
\text { Renal function, hepatic function tests }\end{array}$ \\
\hline $\begin{array}{l}\text { Vascular } \\
\text { access }\end{array}$ & $\begin{array}{l}\text { Presence of two large-bore intravenous cannulae } \\
\text { Previous history of central venous access or thrombosis }\end{array}$ \\
\hline
\end{tabular}

Advice

Anticipate difficulty with intubation

Seek support from the most senior airway specialist available

locally (anaesthetist, neonatologist, ENT specialist)

Ensure naso/oro-gastric tube in place and gastric contents emptied

Oxygen supplementation to avoid hypoxia. If cardiac disease is not confirmed, it is safe to aim for $\mathrm{SpO}_{2}$ target 80-85\%

If available, high-flow nasal cannula therapy or CPAP (including bubble CPAP)

Intubation and ventilation if severe respiratory failure

Early consideration of prostaglandin infusion to maintain ductal patency in suspected CHD

Timely reversal of shock with careful fluid bolus therapy, in small aliquots of $5-10 \mathrm{ml} / \mathrm{kg}$, and inotropic agents such as adrenaline, dopamine, and/or milrinone

Intubation to protect airway if severe coma, responding only to pain, or loss of cough/gag reflexes

Anticonvulsant therapy

Early cranial imaging such as ultrasound and CT scan to rule out bleeding/mass

Continuous ECG monitoring to identify rhythm abnormalities

Urgent correction of hypoglycaemia and hypocalcaemia to maintain cardiac function

Ultrasound-guided venous access, if available

External jugular vein is often patent even in collapsed infants Early intraosseous access in shocked children - upper end of tibia, lower end of femur, and upper end of humerus

$\mathrm{CPAP}=$ continuous positive airway pressure $\mathrm{ENT}=$ ear, nose and throat

cardiac disease should be transported by specialist transport teams. ${ }^{1,5}$ Specialist teams are also more likely to maintain up-to-date skills by regular exposure in clinical practice and during simulated training. Rarely, it may be necessary to transport patients using local staff, mainly owing to lack of timely availability of a specialist team or for time-critical transfers; in these cases, staff with the most experience in managing patient deterioration during transport should accompany the patient. These teams may sometimes be local adult or neonatal critical care transport teams.
Transport equipment. The risk of complications during transport means that children with cardiac disease being transported to a specialist centre should undergo multi-parameter monitoring - continuous echocardiogram and heart rate, oxygen saturations, non-invasive or invasive blood pressure measurement, temperature, and end-tidal $\mathrm{CO}_{2}$ for ventilated patients - using portable, battery-operated monitors. ${ }^{13}$ The team should have access to a portable mechanical ventilator that is batteryoperated, or pneumatically driven, and can ventilate 
patients of various ages - newborn through adolescent. A defibrillator that can be operated in manual mode - ideally combined with transthoracic pacing capabilities - is recommended for most patients. A standardised bag with transport supplies to manage the airway, breathing, and circulation should be available. ${ }^{14}$

Aeromedical transport. The primary motivation for air transport is to achieve a speedy patient transfer to the specialist centre. However, several factors, such as how quickly a helicopter or fixed-wing aircraft is available, how far the landing sites are from both hospitals, and weather considerations, affect any expected time-savings from aeromedical transport. On the other hand, air transport carries small but significant risks to patients and staff. Therefore, the decision to fly must be made after careful consideration of the risks and the expected benefits in each case.

The main patient risks from aeromedical transport relate to physiological changes associated with altitude and the G-forces associated with flight. ${ }^{15,16}$ With increasing altitude, gas expansion can pose a significant problem when it is trapped in a body cavity - for example, pneumothorax, pneumoperitoneum, gastric cavity - or contained within medical equipment - for example, endotracheal tube cuff and urinary catheter cuff. Attention should be paid to draining trapped gases before flying - for example, nasogastric tube on free drainage and chest drain inserted - and to deflate/inflate cuffs during take-off and landing. Hypoxia from flying at an altitude can be dangerous in cardiac disease with preexistent cyanosis - supplemental oxygen may be required. Take-off and landing are particularly dangerous in shock states because of G-forces; therefore, head down or feet up during take-off to prevent pooling of blood in the lower extremities, or the use of fluid boluses to increase preload, may be needed.

Noise and vibration associated with helicopter transport, and the cramped working environment, impose an additional burden on the staff caring for a critically ill child. Ear plugs for children and headsets/helmets for staff should be used to minimise prolonged exposure to noise.

International transports. The main feature of international transports is the long distance involved. For high acuity patients, a dedicated air ambulance may be the most effective means of transport, providing adequate physical space and access to oxygen and/or power; however, in most other cases, a commercial aircraft is preferred owing to speed and the advantage of avoiding multiple refuelling stops. Military aircrafts are also frequently used for international transports. Primary considerations related to such transports are staff numbers and expertise - for example, for long transports stretching over several hours, more than two members of staff may be required to avoid fatigue, and where patient deterioration is expected, staff should be able to provide critical care interventions in flight - and equipment - for example, battery-powered with additional batteries available, ventilators with a compressor-driven turbine to avoid the need for heavy air cylinders and able to function using low-flow oxygen, and ability of equipment to be safely secured in the aircraft. ${ }^{17}$

Transports in resource-limited settings. The limited healthcare infrastructure in low- and middle-income countries poses several different challenges relating to the transport of children with critical cardiac disease. ${ }^{18}$ Many low- and middle-income countries' settings do not have established services for cardiology, cardiac surgery, or paediatric intensive care. As antenatal echocardiography is unavailable, the majority of infants with cardiac disease are born in village health outposts and smaller town health centres/hospitals or at home, and are diagnosed in the postnatal period or later. Vital medications such as prostaglandin may be unavailable, and there is a scarcity of dedicated staff trained in transport. Depending on the complexity of the lesion and the resources available locally, patients may be managed locally awaiting surgical input, by visiting cardiac charity missions such as Chain of Hope, United Kingdom, or International Children's Heart Foundation, United States of America; transported to a larger regional centre where corrective or palliative surgery may be possible; or require international transport to a high-income country for surgical intervention.

The key considerations for transport are the clinical status of the patient, the end point of management, which teams need to be involved in the discussions/ management plan, the distance required to travel, who will accompany the patient on the transfer, what resources are available for the transfer - equipment, mode, and vehicle used - and the discussions with the family/carers/patient. It may be necessary to adapt existing adult ambulances to secure the child using a bassinet, kangaroo pouch, or car seats (Fig 1). There must be a clear plan to ensure continuous monitoring, whether this is direct visualisation or use of limited resources, for example, oximetry. The need for venous access should be assessed, and a decision should be made regarding whether the patient should be fed during the transfer. The practicalities of storage of medications, labelling of drugs, and delivery of intravenous medications under clean conditions should be considered. For long-distance international transports in commercial aircraft, a "grab bag" (limited, essential equipment) should be readily available, and secure venous access should be in place to deliver life-saving medications such as prostaglandin. Most commercial airlines would not be able to deliver oxygen at take-off 
and landing, and it may be necessary to carry portable oxygen cylinders or oxygen concentrators. Secure fixation of equipment to avoid dislodgement during turbulence is an important safety consideration. International volunteer transport teams should be aware of the medicolegal ramifications and ensure that their medical protection unions will cover such activity, keep detailed medical records, and obtain consent from the parents/carers and referring team before undertaking these transfers.

\section{Clinical management during transport}

Key points related to clinical management by the transport team are summarised in Table 2.



Figure 1.

Transporting a neonate with transposition of great arteries in a low-middle income country from hospital to airport for a commercial flight. Note the use of an adult ambulance and the adaptation of a bassinet to secure the child.

\section{Management of specific cardiac conditions during transport}

Specific cardiac conditions are grouped into six clinically relevant categories and key points relating to their management during transport are summarised below.

Antenatally diagnosed CHD. Prostaglandin infusion at small doses $(5-10 \mathrm{ng} / \mathrm{kg} /$ minute) should be used to maintain ductal patency during the transport of the baby to the specialist centre. Intubation is not usually routinely required if the dose does not exceed $15 \mathrm{ng} / \mathrm{kg} /$ minute. ${ }^{19,20}$

The "blue neonate". If the diagnosis is in doubt, a hyperoxia test $-\mathrm{SpO}_{2}$ or $\mathrm{PaO}_{2}$ response to short-term administration of $100 \%$ oxygen - may be helpful to differentiate lung disease from cardiac disease. In most cases of cyanosis where a cardiac cause is suspected, ductal patency should be maintained using a prostaglandin infusion. Intubation is usually required when the dose of prostaglandin infusion is greater than $15 \mathrm{ng} / \mathrm{kg} /$ minute owing to the risk of apnoea.

D-transposition of great arteries. High doses of prostaglandin may be required to reopen a closed duct $(10-20 \mathrm{ng} / \mathrm{kg} /$ minute, $20-50 \mathrm{ng} / \mathrm{kg} /$ minute in some cases). Failure to improve oxygen saturations with a prostaglandin infusion, particularly in a neonate with cyanosis and plethoric lungs, indicates that an urgent balloon atrial septostomy is required, usually under specialist cardiology care. Time to septostomy can be an important factor in the survival and neurodevelopmental outcomes of newborns with $\mathrm{d}$-transposition of the great arteries; therefore, rapid transport is essential. Fluid administration and adrenaline (epinephrine) infusions may be useful but should not delay transport.

Table 2. Key messages for the clinical assessment and stabilisation of children with critical cardiac disease.

Domains Key points for assessment and stabilisation

Airway Reposition airway to maintain patency - roll under the neck, prone position in Pierre Robin syndrome

Endotracheal intubation may be required for transport. Use an intubation checklist to provide a safety net, ensuring that the right people, the right equipment, and the right plans are in place

Have specialist equipment, such as laryngeal mask airway, gum elastic bougie, and video-assisted laryngoscope, available in case of anticipated difficult airway

Use cardiostable induction agents such as ketamine or fentanyl

Use a cuffed endotracheal tube, from $3.5 \mathrm{~mm}$ size upwards

Breathing Use supplemental oxygen to target $\mathrm{SpO}_{2}$ of $75-85 \%$ to avoid pulmonary over-circulation

Use non-invasive respiratory support, such as high-flow nasal cannula and CPAP, for moderate respiratory distress

Provide invasive ventilation if required, with adequate PEEP to support myocardial function and manage pulmonary oedema

Circulation As most cardiac defects in the neonatal period $-<28$ days of age - are likely to have a duct-dependent circulation, either pulmonary or systemic, start prostaglandin (PG) infusion to maintain ductal patency in all suspected cases of CHD Limited fluid resuscitation using $5-10 \mathrm{ml} / \mathrm{kg}$ bolus

Use inotropic support using adrenaline $(0-0.5 \mathrm{mcg} / \mathrm{kg} / \mathrm{min})$, dopamine $(5-10 \mathrm{mcg} / \mathrm{kg} / \mathrm{min})$, and $/$ or milrinone $(0.3-0.7 \mathrm{mcg} / \mathrm{kg} / \mathrm{min})$ infusions

Inotropes can be delivered via peripheral veins if required, although central venous or intraosseous access is safer 
Obstructed total anomalous pulmonary venous return. Urgent transfer for surgery may be required if profound cyanosis unresponsive to conventional therapies - prostaglandin infusion and ventilation suggests a diagnosis of total anomalous pulmonary venous return. The presence of systemic hypoperfusion with lactic acidosis makes the diagnosis of obstructed very likely, but without echocardiography obstructed total anomalous pulmonary venous return is difficult to distinguish from persistent pulmonary hypertension of the newborn, and a short trial of inhaled nitric oxide may be required. Lack of response should lead to termination of the trial of inhaled nitric oxide to avoid further pulmonary vasodilatation; prostaglandin infusion may not always be helpful, but it should always be started to assess response.

The "shocked" neonate. Septic shock and obstruction to systemic cardiac output are the main differential diagnoses to consider in the "shocked" neonate. In most cases of neonatal shock where a cardiac cause is suspected, ductal patency should be maintained using a prostaglandin infusion. Intubation is usually required when the dose of prostaglandin infusion is $>15 \mathrm{ng} / \mathrm{kg} /$ minute or evidence of systemic hypoperfusion is present. Pulmonary over-circulation should be prevented by maintaining a pulmonary to systemic perfusion (Qp:Qs) ratio of 1:1, usually achieved by adjusting the $\mathrm{FiO}_{2}$ to target oxygen saturations of $75-85 \%$ and normalising the $\mathrm{pH}$ and $\mathrm{pCO}_{2}$. Severe acidosis can be treated with sodium bicarbonate to improve myocardial function; intravenous inotropic support can be provided by dopamine and/or adrenaline infusions; and milrinone may be useful to provide lusitropy, inotropy, and to reduce afterload. Blood transfusion to optimise oxygen-carrying capacity and measures to decrease oxygen consumption, such as sedation, muscle relaxation, and avoidance of hyperthermia, should also be considered. In hypoplastic left heart syndrome with a restrictive atrial connection, shock does not respond to conventional management, indicating a specific situation in which a "time-critical" transfer to the specialist centre will be required.

The "blue" infant or child. Cyanosis may be a presenting feature in a child in the setting of undiagnosed cyanotic heart disease, repaired heart defects, or from pulmonary pathology. The management of spells during transport in cases of tetralogy of Fallot involves the administration of $100 \%$ oxygen, intravenous morphine, $\beta$-blockers such as propranolol, fluid bolus to increase preload, and increasing the systemic vascular resistance by vasoconstrictors such as phenylephrine, metaraminol, or noradrenaline infusion. Intubation and ventilation may be required when response to conventional treatment is inadequate and/or if repeated spells occur in a short period of time, with associated metabolic acidosis. In cases of blocked systemicpulmonary shunt, fluid volume administration and intravenous heparin are indicated, with rapid transfer to the specialist centre for urgent intervention.

The infant or child in beart failure. Main treatment principles include oxygen therapy, judicious fluid management to avoid fluid overload, diuretic therapy, and support for the failing myocardium. Myocardial support can be provided by positive pressure ventilation, either using non-invasive ventilation or intubation and ventilation. Support for the failing myocardium can be provided by the use of inotrope infusions (adrenaline, dopamine, dobutamine, or milrinone).

The child with an abnormal heart rhythm. Minimum monitoring during transport should include continuous electrocardiogram, pulse oximetry, regular blood pressure, and respiratory rate, and defibrillation pads should be in place on the child during the transport in preparation for intervention. A defibrillator capable of delivering synchronous and asynchronous direct current (DC) shocks, as well as transthoracic pacing, should be readily available.

Supraventricular tachycardia. If adenosine fails to restore sinus rhythm and shock persists, or if intravenous access is not available, synchronised cardioversion $(1 \mathrm{~J} / \mathrm{kg})$ should be administered. Cardioversion will usually require an infant's airway to be stabilised by intubation first, although older children can be managed with sedation alone - using midazolam or ketamine. An infusion of amiodarone, at a loading dose of $25 \mu \mathrm{g} / \mathrm{kg} /$ minute for 4 hours, and then $5-10 \mu \mathrm{g} / \mathrm{kg} /$ minute, should be considered in refractory cases.

Ventricular tachycardia. Haemodynamic instability should be managed with DC cardioversion (1-2 J/kg) once the airway and breathing have been stabilised. Polymorphic ventricular tachycardia - torsades de pointes - can be treated with intravenous magnesium sulphate $(25 \mathrm{mg} / \mathrm{kg})$.

Complete heart block. Stabilisation and initiation of agents such as isoprenaline or adrenaline infusions may be used to increase the heart rate. In refractory complete heart block, transcutaneous pacing may be required during transport.

\section{Conclusion}

With increasing focus on the centralisation of specialist services in fewer centres, or lack of specialist 
services in many parts of the world, the need for inter-hospital transport of children with critical cardiac disease is only likely to rise. The key principles of safe transport include robust triage and advice provision, clinical stabilisation before transport, and anticipation of potential complications during transport.

\section{Acknowledgements}

None.

\section{Financial Support}

This research received no specific grant from any funding agency, commercial, or not-for-profit sectors.

\section{Conflicts of Interest}

None.

\section{References}

1. Ramnarayan P, Thiru K, Parslow RC, et al. Effect of specialist retrieval teams on outcomes in children admitted to paediatric intensive care units in England and Wales: a retrospective cohort study. Lancet 2010; 376: 698-704.

2. NHS England. New congenital heart disease review: final report. London, 2015.

3. Lundstrom NR, Berggren H, Bjorkhem G, et al. Centralization of pediatric heart surgery in Sweden. Pediatr Cardiol 2000; 21: 353-357.

4. Orr RA, Kuch BA. Triage and Transport of Infants and Children with Cardiac Disease. In: Munoz R, (ed.). Critical Care of Children With Heart Disease: Basic Medical and Surgical Concepts. Springer-Verlag, London, 2010: 13-21.

5. Orr RA, Felmet KA, Han Y, et al. Pediatric specialized transport teams are associated with improved outcomes. Pediatrics 2009; 124: $40-48$.
6. Warren J, Fromm RE Jr, Orr RA, et al. Guidelines for the interand intrahospital transport of critically ill patients. Crit Care Med 2004; 32: 256-262.

7. Department of Health. The acutely or critically sick or injured child in the district general hospital: a team response. London, 2006.

8. Ostermayer DG, Gausche-Hill M. Supraglottic airways: the history and current state of prehospital airway adjuncts. Prehosp Emerg Care 2014; 18: 106-115.

9. Fiorito BA, Mirza F, Doran TM, et al. Intraosseous access in the setting of pediatric critical care transport. Pediatr Crit Care Med 2005; 6: 50-53.

10. Satou GM, Rheuban K, Alverson D, et al. Telemedicine in pediatric cardiology: a scientific statement from the American Heart Association. Circulation 2017; 135: e648-e678.

11. Dayal P, Hojman NM, Kissee JL, et al. Impact of telemedicine on severity of illness and outcomes among children transferred from referring emergency departments to a children's hospital PICU. Pediatr Crit Care Med 2016; 17: 516-521.

12. Perez A, Butt WW, Millar KJ, et al. Long-distance transport of critically ill children on extracorporeal life support in Australia. Crit Care Resusc 2008; 10: 34.

13. Sarfatti A, Ramnarayan P. Transport of the critically ill child. Paediatr Child Health, 27: 222-228.

14. Dawes J, Ramnarayan P, Lutman D. Stabilisation and transport of the critically ill child. J Intens Care Soc 2014; 15: 34-42.

15. Valente ME, Sherif JA, Azen CG, et al. Cerebral oxygenation and acceleration in pediatric and neonatal interfacility transport. Air Med J 2016; 35: 156-160.

16. Farmer JC. Respiratory issues in aeromedical patient transport. Respir Care Clin N Am 1996; 2: 391-400.

17. Beninati $\mathrm{W}$, Jones KD. Mechanical ventilation during long-range air transport. Respir Care Clin N Am 2002; 8: 51-65.

18. Duke T. Transport of seriously ill children: a neglected global issue. Intens Care Med 2003; 29: 1414-1416.

19. Meckler GD, Lowe C. To intubate or not to intubate? Transporting infants on prostaglandin E1. Pediatrics 2009; 123: e25-e30.

20. Browning Carmo KA, Barr P, West $\mathrm{M}$, et al. Transporting newborn infants with suspected duct dependent congenital heart disease on low-dose prostaglandin E1 without routine mechanical ventilation. Arch Dis Child Fetal Neonatal Ed 2007; 92: F117-F119. 